\title{
MicroRNA-Gene Signaling Pathways in Pancreatic Cancer
}

\author{
Alexandra Drakaki ${ }^{1}$, Dimitrios Iliopoulos ${ }^{2}$
}

\begin{abstract}
Pancreatic cancer is the fourth most frequent cause of cancer-related deaths and is characterized by early metastasis and pronounced resistance to chemotherapy and radiation therapy. Despite extensive research efforts, there is not any substantial progress regarding the identification of novel drugs against pancreatic cancer. Although the introduction of the chemotherapeutic agent gemcitabine improved clinical response, the prognosis of these patients remained extremely poor with a 5-year survival rate of 3-5\%. Thus, the identification of the novel molecular pathways involved in pancreatic oncogenesis and the development of new and potent therapeutic options are highly desirable. Here, we describe how microRNAs control signaling pathways that are frequently deregulated during pancreatic oncogenesis. In addition, we provide evidence that microRNAs could be potentially used as novel pancreatic cancer therapeutics through reversal of chemotherapy
\end{abstract} and radiotherapy resistance or regulation of essential molecular pathways.

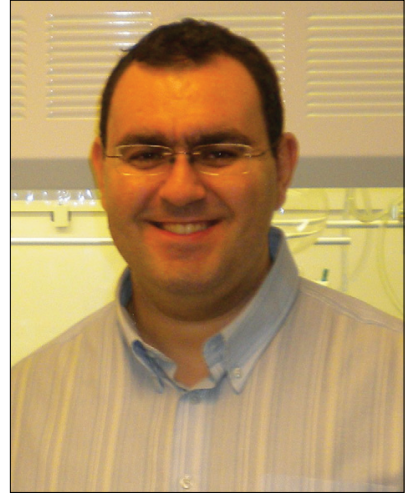

Prof. Dimitrios Iliopoulos Further studies should integrate the deregulated genes and microRNAs into molecular networks in order to identify the central regulators of pancreatic oncogenesis. Targeting these central regulators could lead to the development of novel targeted therapeutic approaches for pancreatic cancer patients. (Biomed J 2013;36:200-208)

\section{Key words: genes, microRNAs, networks, pancreatic cancer, systems biology}

$\mathrm{P}$ ancreatic adenocarcinoma (PDAC) is the most common type of pancreatic cancer constituting more than $85 \%$ of pancreatic tumors ${ }^{[1]}$ and is the fourth leading cause of cancer mortality in the United States. ${ }^{[2]}$ At the time of diagnosis, more than $75 \%$ of patients will have locally advanced or metastatic disease, with up to $80 \%$ of the patients having unresectable disease. ${ }^{[3]}$ The median survival of those patients with locally advanced and metastatic disease is up to 10 months and up to 6 months, respectively, with an overall 5 -year survival of less than 5\%. The incidence almost correlates with the death rate, underscoring the high fatality rate of this aggressive disease. The new cases for the year 2012 were estimated to be approximately 44,000, with more than 37,000 deaths. ${ }^{[4]}$

Despite extensive research approaches, novel drugs have not been added in the treatment landscape for this disease. Thus, the identification of the essential molecular pathways involved in pancreatic oncogenesis will play a pivotal role in the development of new and potent therapeutic options. Recently, microRNAs, which are small non-coding genes, have been identified to be deregulated and being involved in the pathogenesis of pancreatic cancer. ${ }^{[5]}$

Here, we describe how microRNAs regulate different signaling pathways contributing to pancreatic oncogenesis and discuss how targeting these microRNA pathways could lead to the identification of novel compounds that could be transferred from the bench to the bedside for the treatment of patients with pancreatic cancer.

\section{The role of microRNAs in oncogenesis}

MicroRNAs are small non-coding RNAs of 19-24 nucleotides length that regulate gene expression through mRNA cleavage or translational inhibition. It has been shown that microRNAs act through binding directly in the 3

From the ${ }^{1}$ Division of Hematology/Oncology, Department of Medicine, Beth Israel Deaconess Medical Center, Boston, MA, USA; ${ }^{2}$ Center for Systems Biomedicine, Division of Digestive Diseases, David Geffen School of Medicine, University of California Los Angeles,

Los Angeles, CA, USA

Received: Jun. 4, 2012; Accepted: Mar. 15, 2013

Correspondence to: Prof. Dimitrios Iliopoulos, Center for Systems Biomedicine, Division of Digestive Diseases, David Geffen School of Medicine, University of California at Los Angeles, USA. 650 Charles E. Young Dr., CHS 44-133, Los Angeles, CA 90095-7278, USA. Tel: 310-825-8856; Fax: 310-825-9253; E-mail: diliopoulos@ mednet.ucla.edu

DOI: $10.4103 / 2319-4170.119690$ 
untranslated region (UTR) of genes and specifically through sequence complementarity between nucleotides 2 and 8 of the microRNA (called seed sequence) and the 3'UTR of a gene. ${ }^{[6]}$ Thousands of studies have revealed a central role for microRNAs in the regulation of essential processes such as proliferation, ${ }^{[7]}$ apoptosis,${ }^{[8]}$ and inflammation. ${ }^{[9-12]}$ Calin et al., provided the first evidence that microRNAs are deregulated in cancer and specifically miR-15a and miR-16 are down-regulated or deleted in the majority of patients with chronic lymphocytic leukemia (CLL). ${ }^{[13]}$ Aberrant microRNA expression has also been linked to cancer, with more than $50 \%$ of the microRNAs being identified within genomic regions which are associated either with fragile sites or with carcinogenesis. ${ }^{[14]}$ These small non-coding RNAs when are down-regulated act as tumor suppressors, while they act as oncogenes when they are overexpressed. ${ }^{[15]}$ Advances in the available technologies to profile microRNA expression levels exploded the microRNA field and led to the identification of microRNAs that are deregulated in most cancer types, including pancreatic cancer. ${ }^{[16]}$

\section{MicroRNAs deregulated in early steps of pancreatic oncogenesis}

Previous studies have shown that microRNAs exhibit tissue-specific and disease-specific expression that can differentiate between benign tissues and cancer as well as between different tumor types. ${ }^{[17]}$ Bloomston et al., identified a microRNA signature that discriminated different stages of pancreatic oncogenesis, including potentially precancerous stages such as chronic pancreatitis. ${ }^{[5]}$ Specifically, in this study, 8 microRNAs (miR-494, miR-483, miR-339, miR-218, miR-148a, miR-375, miR-409, and miR-148b) were down-regulated and 15 microRNAs (miR-96, miR-221, miR-34, miR-497, miR-203, miR-155, miR-181a, miR-453, miR-92, miR-181b, miR-181d, miR-93, miR-181b-1, miR-21, and miR-181c) were up-regulated in pancreatic cancer samples relative to tissues from patients with chronic pancreatitis. Similarly, two microRNAs (miR-96 and miR-497) were down-regulated while 22 microRNAs (miR-494, miR-483, miR-383, miR-197, miR-339, miR-194, miR-198, miR-409, miR-199b, miR-199a-2, miR-199a-1, miR-7-3, miR-128b, miR-100, miR-125a, miR-125b-2, miR-195, miR-126, miR-125b-1, miR-100, miR-10b, and miR-99) were up-regulated in chronic pancreatitis samples when compared to normal pancreatic tissues. More importantly, a subset of 21 up-regulated and 4 down-regulated microRNAs were identified that could differentiate between PDAC and normal pancreatic tissues. Among all these microRNAs, it has been demonstrated that up-regulation of microRNAs miR-155, miR-181a, b, c, d, miR-21, and miR-221, as well as down-regulation of miR-148a, b and miR-375 could distinguish PDAC from normal pancreas and pancreatitis samples. In addition, another study by Szafranska et al., analyzed the expression levels of 377 microRNAs from pancreatic ductal adenocarcinoma tissues, normal pancreas, and chronic pancreatitis samples by using microRNA microarray technology. ${ }^{[18]}$ Interestingly, they identified a series of microRNAs that were deregulated in both pancreatitis and cancer samples compared to normal tissues. Those were: miR-29c, miR-96, miR-143, miR-148b, and miR-150. In the same study, the authors suggested that only two microRNAs (miR-217 and miR-196a) could distinguish between PDAC from normal pancreas and pancreatitis. All these data suggest that microRNAs are deregulated in pancreatitis, suggesting their involvement in the development of pancreatic carcinogenesis.

\section{MicroRNA-gene signaling pathways in pancreatic oncogenesis}

In the last few years, there has been increasing knowledge about the signaling pathways that are deregulated during pancreatic oncogenesis. However, the role and regulation of these signaling pathways involved in pancreatic tumor initiation and progression remain to be thoroughly clarified. Below we describe the microRNAs that are deregulated in pancreatic cancer and control essential molecular pathways that have been found to be involved in pancreatic oncogenesis [Table 1].

\section{K-Ras signaling pathway}

One of the most frequently activated oncogenes in up to $25 \%$ of all human cancers is the activating mutations of the Kirsten rat sarcoma virus (K-Ras). Almost exclusively all pancreatic cancers have this molecular signature, making this mutation the most well studied in the pancreatic cancer research field ${ }^{\left[{ }^{[19]}\right.}$ It is an early event in PDAC formation that increases in frequency with disease progression. ${ }^{[20]}$

$\mathrm{K}-\mathrm{R}$ as is a $21 \mathrm{kDa}$ intracellular membrane-bound protein that belongs to the GTPase superfamily and plays a significant role in cell survival, proliferation, and migration. ${ }^{[21]} \mathrm{K}-$ Ras is activated initially by binding of various growth factors to the membrane-bound receptors. ${ }^{[22]}$ Following that, the adaptor protein GRB2 is recruited leading to subsequent recruitment to the cell membrane of the guanine exchange factors (SOS1 and CDC25). ${ }^{[23]}$ This chain of interactions occurs concurrently with the transition of Ras-GDP to the Ras-GTP activated protein form. In physiological conditions, the GAP proteins and, specifically, the RAS GTPases do promote GTP hydrolysis and reversal of the Ras activation step. ${ }^{[2]}$ During oncogenic transformation, Ras is mutated and constitutively activated and cannot be deactivated by the GAP proteins. ${ }^{[24]}$ All these data suggest that the K-Ras signaling pathway is a central regulator of pancreatic tumor initiation and progression. 
Table 1: MicroRNA-gene pathways in pancreatic cancer

\begin{tabular}{|c|c|c|c|c|}
\hline Pathway & MicroRNA & Levels in tumors & Targets & Ref. \\
\hline \multirow[t]{6}{*}{ K-Ras } & miR-217 & Down-regulated & K-RAS & 25 \\
\hline & miR-96 & Down-regulated & K-RAS & 26 \\
\hline & miR-126 & Down-regulated & K-RAS, CRK & 27 \\
\hline & let-7 & Down-regulated & K-RAS & 27 \\
\hline & miR-143/145 & Down-regulated & K-RAS, RREB1 & 28 \\
\hline & miR-21 & Up-regulated & PTEN, PDCD4 & 29 \\
\hline \multirow[t]{2}{*}{ PI3K-AKT } & $\operatorname{miR}-217$ & Down-regulated & AKT & 25 \\
\hline & miR-96 & Down-regulated & $\mathrm{AKT}$ & 26 \\
\hline Notch & miR-144 & Down-regulated & Notch-1 & 46 \\
\hline \multirow[t]{4}{*}{ Angiogenesis } & $\operatorname{miR}-210$ & Up-regulated & NPTX1, EFNA3 & 50 \\
\hline & miR-155 & Up-regulated & HIF-1a, VEZF1 & 50 \\
\hline & miR-222 & Up-regulated & c-kit, VEZF2, ANGPTL2 & 51,52 \\
\hline & miR-203 & Up-regulated & EphA2, EphB7 & 51 \\
\hline \multirow[t]{7}{*}{ Cell cycle } & miR-222 & Up-regulated & p27, p57, TP53INP1 & 51 \\
\hline & miR-203 & Up-regulated & TP53INP1, ELAVL2 & 51 \\
\hline & miR-155 & Up-regulated & LDOC1, TP53INP1 & 51 \\
\hline & miR-148 & Down-regulated & AMPK & 60 \\
\hline & miR-34a & Down-regulated & CDK6 & 61 \\
\hline & miR-132 & Up-regulated & $\mathrm{Rb} 1$ & 62 \\
\hline & miR-212 & Up-regulated & $\mathrm{Rb} 1$ & 62 \\
\hline Hedgehog & miR-3548 & Down-regulated & Gli-1 & 73 \\
\hline
\end{tabular}

Several recent studies have identified specific microRNAs that regulate the K-Rassignaling pathway in pancreatic oncogenesis. MiR-217 has been identified to be down-regulated in PDAC tissues and cell lines relative to normal, suggesting its tumor suppressor function in pancreatic cancer. Interestingly, K-RAS is a direct target of miR-217, and miR-217 overexpression results in decreased K-Ras protein levels. ${ }^{[25]}$ Similarly, another study has identified that miR-96 targets directly K-RAS oncogene, suggesting the presence of microRNAs that act as direct regulators of K-Ras levels in pancreatic cancer. ${ }^{[26]}$

A study by Jiao et al., showed that miR-126 and let-7, which regulate the K-Ras-driven oncogenic pathways, are down-regulated in PDAC compared to normal tissues, thus stimulating the oncogenic transformation. ${ }^{[27]}$ On the other hand, it has been shown that K-RAS activation suppresses the expression of the miR-143/145 cluster via the Ras-responsive element-binding protein (RREB1). Importantly, reduced expression of the miR-143/145 cluster has been observed in K-RAS mutant pancreatic cancers. Specifically, miR-143/145 cluster targets both K-RAS and RREB1, leading to a feedback circuit that potentiates Ras signaling. ${ }^{[28]}$ Finally, miR-21, a well-known oncogenic microRNA including PDAC, has been found to be up-regulated very early during the transformation process. Specifically, preclinical studies have shown that K-RAS regulates miR-21 expression levels in precancerous lesions (PanIN) and the peak of miR-21 expression correlates with the degree of progression to more aggressive forms. ${ }^{[29]}$

\section{PI3K-AKT signaling pathway}

The phosphatidylinositol-3-kinases (PI3K), which constitute a complex family of lipid kinases, are implicated in different cellular functions such as cell survival, proliferation, differentiation, chemotaxis, and glucose homeostasis. ${ }^{[30]}$ The downstream signals of the PI3K are mediated through the Akt murine thymoma viral oncogene (AKT) survival signaling kinase AKT, through pro-apoptotic proteins such as caspase- 9 and Bad, plays a critical role in the regulation of apoptosis. ${ }^{[31]} \mathrm{PI} 3 \mathrm{~K}$ signaling pathway is a major effector of K-Ras pathway and is necessary for growth and survival of pancreatic cancer cells. ${ }^{[32]}$ One of the important targets of the PI3K pathway is Rac, which is a $\mathrm{G}$ protein that can be activated by phosphatidyl 3,4,5-triphosphate (PIP3). ${ }^{[33]}$ The Rac protein through nuclear factor (NF)- $\mathrm{\kappa B}$ regulates anti-apoptotic gene expression and so plays a significant role in pancreatic tumorigenesis. ${ }^{[34]}$

Recently, we have identified microRNAs to be directly regulated by the AKT signaling pathway, specifically the different AKT isoforms. ${ }^{[35]}$ Interestingly, several of these microRNAs, including miR-145, miR-34, miR-200b, and miR-200c, have been found to be deregulated during pancreatic oncogenesis. On the other hand, several studies have identified microRNAs to regulate the PI3K-Akt pathway at different levels. Specifically, miR-217 and miR-96 have been identified to suppress AKT phosphorylation levels in pancreatic cancer. ${ }^{[25]}$ In addition, miR-21 has been found to control the Akt signaling pathway through direct regulation 
of phosphatase and tensin homolog (PTEN) tumor suppressor gene in pancreatic cancer ${ }^{[36]}$ Also, another study showed that proliferation and colony formation of pancreatic cancer cells were suppressed in cells transfected with miR-132 and enhanced in cells transfected with miR-132 inhibitor by negatively regulating the Akt signaling pathway. ${ }^{[37]}$

\section{Notch signaling pathway}

Notch proteins are known type I transmembrane protein family members that function as receptors for membrane-bound ligands. The most characteristic feature of the Notch pathway is lateral inhibition. ${ }^{[38]}$ Through lateral inhibition, a single cell is programmed to differentiate, while its neighboring cells remain undifferentiated. Interestingly, this process of lateral inhibition mediated by the Notch pathway is significant for pancreas development during embryogenesis. ${ }^{[39]}$ Specifically, the extracellular domain of the Notch protein interacts with a ligand bound to a neighboring cell. After ligand-ligand interaction, tumor necrosis factor-alpha converting enzyme (TACE) cleaves the Notch protein, releasing the extracellular portion of the protein and allowing the cytoplasmic portion to be enclosed. The intracellular portion of the Notch protein is then modified and eventually translocates to the nucleus where it activates gene transcription. ${ }^{[40]}$ Activation of the Notch pathway has been implicated in PDAC and oncogenic transformation. ${ }^{[41]}$ Interestingly, overexpression of the Notch signaling cascade correlates with overexpression of vascular endothelial growth factor (VEGF), suggesting a crosstalk between these two and likely with other oncogenic pathways ${ }^{[42]}$ On the other hand, concurrent inhibition of the EGF and Notch signaling pathways does result in decreased cell proliferation with concomitant increase in cell apoptosis. ${ }^{[39]}$ This inhibition also results in decrease of the NF- $\mathrm{\kappa B}$ activity and up-regulation of the p21 and p27. ${ }^{[43]}$ Therefore, Notch pathway plays a critical role in pancreatic oncogenesis.

Several studies have shown that the Notch signaling pathway is regulated by microRNAs during pancreatic oncogenesis. Preclinical studies have shown that p53 directly regulates miR-34 which downstream targets Notch and, therefore, plays a role in the maintenance and survival of pancreatic cancer initiating cells. ${ }^{[44]}$ On the other hand, re-expression of miR-34 inhibits invasion, pancreatic cell growth, and eventually leads to apoptosis. ${ }^{[45]} \mathrm{A}$ recent study identified DCAMKL-1 as a stem cell marker expressed in a subset of cells in human pancreatic tumors. In vitro studies have shown that knockdown of DCAMKL-1 led to the down-regulation of the Notch signaling pathway through an miR-144 microRNA-dependent mechanism. ${ }^{[46]}$ On the other hand, activation of Notch-1 signaling leads to elevated levels of miR-21 and decreased expression of the miR-200 and let-7, conferring epithelial-mesenchymal transition (EMT) properties and, therefore, a highly aggressive phenotype. ${ }^{[47]}$ Specifically, a recent study showed that miR-200 members target Notch pathway components, such as Jagged1 (Jag1), and the mastermind-like co-activators Maml2 and Maml3 in pancreatic cancer ${ }^{[48]}$ Taken together, all these suggest that microRNAs are essential regulators of the Notch signaling pathway in pancreatic cancer.

\section{The angiogenesis pathway}

Angiogenesis plays a pivotal role in PDAC genesis and progression. Hypoxia is involved in this pathway through induction of the hypoxia-inducible factor (HIF) that eventually leads to increased expression of VEGF. ${ }^{[49]}$ MiR-155 targets HIF-1 alpha which induces directly miR-210, as well as miR-21 under hypoxia. ${ }^{[50]}$ Other microRNAs that are involved in the angiogenesis pathway are miR-203 and miR-222. ${ }^{[51]}$ Interestingly, in vitro studies have shown that miR-222 affects c-kit expression and, therefore, controls angiogenesis. ${ }^{[52]}$

\section{Cell cycle signaling pathway}

Cell cycle regulation is crucial for cell survival and several cyclin and cyclin-dependent kinases have been identified to be involved in the cell cycle signaling pathways. P16 is a central regulator of G1-S cell cycle phase through inhibition of retinoblastoma (RB) phosphorylation and blockage of the E2F release. ${ }^{[53]}$ It has been shown that approximately $95 \%$ of pancreatic cancers have a loss of function of the p16 (also named INK4A). ${ }^{[54]}$ This gene is inactivated in pancreatic tumors due to deletion or promoter hypermethylation. ${ }^{[55,56]}$ Furthermore, it has been proposed that patients with inactive 16 have larger tumors and shorter survival, suggesting its essential role in the aggressiveness of PDACs. ${ }^{[57]}$ The locus that encodes the p16 protein also encodes the alternative open reading frame (ARF) -protein; however, they do not share any amino acid homology In addition, ARF protein has been found to induce G1 arrest through p53-dependent mechanisms. ${ }^{\left[{ }^{[3]}\right.}$ Animal studies have shown that mutations in both K-RAS and INK4A/ARF in mice result in the development of pancreatic tumors leading to subsequent death of the animals. ${ }^{[58]}$

Not surprisingly, there are several microRNAs that participate in the deregulation of the cell cycle genes that are essential during pancreatic oncogenesis. Specifically, miR-222 targets p27 (Kip1) and p57 (Kip2) which are cell cycle inhibitors. Up-regulation of miR-222 is not sufficient for uncontrolled proliferation, but does empower the cells to enter the S-phase. Along with miR-222, miR-203 and miR-155 target p53 which is another crucial regulator of the cell cycle. ${ }^{[51]}$ Another microRNA that acts as a tumor suppressor and is down-regulated in pancreatic cancer is miR-148. It is believed that the mechanism that leads to 
miR-148 silencing is hypermethylation that occurs as an early event during pancreatic carcinogenesis ${ }^{[59]}$ In vitro and in vivo studies have shown that miR-148 directly targets AMP activated protein kinase (AMPK) that plays a key role as a master regulator of cellular energy homeostasis, and through that interaction, it inhibits the growth of the cancer cells and also induces cell cycle arrest and apoptosis. ${ }^{[60]}$ Similarly, methylation of the promoter of miR-34a leads to its down-regulation, while re-expression in pancreatic cancer cell lines induces senescence and cell cycle arrest via targeting the cyclin-dependent kinase 6 (CDK6) ${ }^{[61]}$ On the other hand, miR-132 and miR-212 are overexpressed in PDAC tissues compared to normal tissues. Both are predicted to target the retinoblastoma (Rb1) tumor suppressor and so reduce its levels. Down-regulation of miR-132/212 eventually causes $\mathrm{G}(2) / \mathrm{M}$ cell cycle arrest and reduces cell proliferation. ${ }^{[62]}$ These data reveal the strong microRNA regulation of cell cycle-related pathways during pancreatic oncogenesis.

\section{Her2/neu signaling pathway}

ErbB2 (known also as Her2/neu) is a 185 kDa glycoprotein receptor that has a structure similar to that of epidermal growth factor receptor (EGFR). Her2 dimerizes with EGFR and forms a heterodimer that stabilizes EGFR ligand binding and enhances kinase-mediated activation of various downstream signaling pathways such as the PI3K and mitogen activated protein kinase (MAPK) pathways. Among the gastrointestinal malignancies, Her2 overexpression has a significant clinical and therapeutic implication in gastric cancer. ${ }^{[63]}$ Similarly, up to $25 \%$ of PDACs have Her2/neu gene amplification, as demonstrated by fluorescence in-situ hybridization (FISH). ${ }^{[64]}$ Buchler et al., showed that herceptin, a known monoclonal antibody against Her2/neu, that has proven efficacy in Her2-positive breast and gastric cancer, does suppress tumor growth in vivo and in vitro in pancreatic cancer cell lines. ${ }^{\left[{ }^{[6]}\right.}$ Interestingly, there is direct correlation between the expression levels of the Her2/neu and the shorter survival in patients with pancreatic cancer, suggesting that the HER-2 signaling pathway is a central regulator of pancreatic oncogenesis. ${ }^{[66]}$ The Her2/neu pathway is primarily studied in breast cancer cell lines, where miR-21 expression levels correlate with the Her2/neu up-regulation. The miR-21 acts as an oncogene that directly targets and so decreases the metastasis suppressor protein, programmed cell death 4 (PDCD4). ${ }^{[67]}$ It will be interesting to study if miR-21 regulates Her2 signaling pathway in pancreatic cancer similar to breast cancer.

\section{Hedgehog signaling pathway}

Another critical pathway in the initiation and maintenance of pancreatic carcinogenesis is the hedgehog pathway.
The hedgehog protein is made as a precursor that is autocatalytically cleaved and attached to the cell surface, thereby preventing it from being diffused freely. ${ }^{[68]}$ Therefore, these proteins are capable of autocrine and paracrine signaling. When the cell receives the hedgehog signals, it expresses the membrane-bound proteins, Patched and Smoothened. ${ }^{[69]}$ In the absence of the Hedgehog signaling, the Patched receptor suppresses the activity of the transmembrane receptor, Smoothened. However, in the presence of the Hedgehog signaling and binding to the Patched protein, the Smoothened receptor is de-repressed, translocates to the cell membrane, leading to activation of this protein with resultant translocation of Gli protein to the nucleus and activation of gene transcription. ${ }^{[70]}$ The Hedgehog signaling pathway is identified early in the pancreatic intraepithelial neoplasia progression and is deregulated in the majority of the PDACs, where it enhances proliferation of pancreatic ductal epithelial cells through MAPK and PI3K signaling pathways. ${ }^{[71]} \mathrm{A}$ recent study revealed that a sonic hedgehog inhibitor (cyclopamine) regulated the expression levels of several microRNAs (let-7, miR-34, miR-125, miR-128, miR-130, miR-132, miR-107, and miR-141) in pancreatic cancer cells. ${ }^{[72]}$ Importantly, another study showed that miR-3548 regulates directly Gli-1 expression levels, controlling pancreatic tumor cell proliferation. ${ }^{[73]}$

\section{MicroRNAs and metastasis in pancreatic cancer}

There are numerous studies that strongly describe the metastatic potential of tumors due to the deregulated microRNA expression. It is known that EP300, which is a histone acetyltransferase that regulates transcription through chromatin remodeling, plays a significant role in cell growth. This enzyme is down-regulated in cancer cells with increased metastatic potential and, therefore, is considered a metastatic suppressor. ${ }^{[74]}$ Mees et al., identified a group of microRNAs (miR-194, miR-200b, miR-200c, and miR-429) that are significantly up-regulated in metastatic pancreatic cancer cells lines compared to low or non-metastatic pancreatic cell lines. Through direct targeting of the EP300, these microRNAs promote metastasis. ${ }^{[75]}$ Similarly, miR-224 and miR-486 target CD40, which is a tumor necrosis factor receptor family member. It has an important anti-tumor immune response role and is a mediator of metastasis when it is down-regulated by these two microRNAs. ${ }^{[76]}$

On the other hand, several microRNAs have been identified as being metastasis suppressors. Li et al., described that in pancreatic cell lines, ectopic expression of miR-146a down-regulated NF- $\mathrm{KB}$ regulatory kinase, EGFR, and interleukin 1 receptor-associated kinase 1 (IRAK-1), leading to inhibition of the invasiveness of these pancreatic cell lines. ${ }^{[77]}$ Likewise, miR-520h has been shown to have anti-metastatic role through direct inhibition of the gene 
expression of ATP-binding cassette subfamily $\mathrm{G}$ member 2 (ABCG2), which is also known as breast cancer resistance protein. ${ }^{[78]}$ Also, Yan et al., demonstrated that miR-20, which is a member of the miR-17-92 family, has a metastatic suppressing effect. Specifically, miR-20 regulates negatively signal tranducer and activator of transcription 3 (STAT3) and inhibits the proliferation and invasiveness of pancreatic cancer cell lines. ${ }^{[79]}$ Finally, the miR-200 family genes act as potential tumor suppressors by targeting two important E-box binding transcription factors (ZEB1 and ZEB2). The microRNA-induced down-regulation of ZEB1/2 is considered responsible for EMT. ${ }^{[80]}$ During EMT, there is a gain of stem cell properties, and therefore, the putative stem cell marker DCAMKL-1 is up-regulated. A recent study by Sureban et al., described that siRNA-mediated knockdown of DCAMKL-1 induces miR-200 as well as down-regulates c-Myc and K-RAS through a let-7dependent mechanism. ${ }^{[46]}$ Overall, these data suggest the involvement of microRNAs in the metastatic processes of pancreatic tumors.

\section{Therapeutically targeting microRNAs in pancreatic cancer}

Pancreatic cancer remains one of the most fatal types of cancer with the only possible curative treatment being surgical resection, but the greatest percentage of patients having unresectable disease at the time of diagnosis. Therefore, improvement in the outcome of patients with advanced or metastatic pancreatic cancer is dependent primarily on the development of more effective systemic therapies that can control tumor growth. The standard of care for advanced pancreatic cancer is gemcitabine with 5.6 months of median survival and $18 \%$ 1-year survival. ${ }^{\left[{ }^{11]}\right.}$ For patients with good performance status, Folfirinox showed a survival benefit compared to gemcitabine, although with significant associated toxicity. Regardless of the treatment approach, eventually all the patients develop resistance to the conventional chemotherapy. ${ }^{[82]}$

Interestingly, several microRNAs have been linked to induce chemo-sensitivity or chemo-resistance in different pancreatic cell lines. Specifically, miR-21 has been shown to induce chemo-resistance to gemcitabine in vitro. High level of miR-21 is associated with poor survival. ${ }^{[83]}$ On the other hand, inhibition of miR-21 decreases cell proliferation and induces apoptosis. ${ }^{[84]}$ Based on these observations, Hwang et al., demonstrated that miR-21 could not only be a biomarker for prediction of chemo-resistance but also low levels of miR-21 could correlate with high 5-fluorouracil (5-FU) chemo-sensitivity. ${ }^{[85]}$ Like miR-21, miR-200 is involved in chemo-sensitivity of pancreatic cancer cells. Recently, Ali et al., described that decreased expression of miR-200 and increased expression of miR-21 are associated with gemcitabine resistance in pancreatic cancer cell lines. ${ }^{[36]}$ MiR-34 has low levels in pancreatic tumors and has tumor suppressor properties. Chang et al., showed that restoration of miR-34 enhances chemo-sensitivity as well as radio-sensitivity in pancreatic cancer cell lines. ${ }^{[86]}$ Impressively, in vivo overexpression of miR-34 led to more than $80 \%$ reduction of the tumor initiating cell population and inhibition of the tumor sphere growth. ${ }^{[45]}$

In addition to reversing the chemo- and radio-resistance of pancreatic tumors, recent studies have identified that manipulation of microRNA expression levels could have therapeutic effects by suppressing pancreatic tumor growth. Specifically, Gironella et al., have shown that restoration of miR-155 expression suppresses pancreatic tumor development, ${ }^{[87]}$ while another study found that miR-146a and miR-20a overexpression suppressed the invasiveness of pancreatic cancer cells. ${ }^{[77,79]}$

\section{Conclusions and future perspectives}

The identification of novel deregulated microRNA signaling pathways in pancreatic cancer not only broadens our understanding of the molecular mechanisms involved in pancreatic oncogenesis but also provides new avenues for the development of novel targeted therapeutic approaches. Previous studies have described multiple deregulated microRNAs and genes in different steps of pancreatic oncogenesis. Future studies should integrate these alterations into molecular networks in order to identify the central regulators and drivers of pancreatic tumorigenesis. Furthermore, development of microRNA delivery vectors and particles would be essential for the potential transfer and use of microRNAs as therapeutic agents in pancreatic cancer.

\section{REFERENCES}

1. Klimstra DS, Adsay N. Benign and malignant tumors of the pancreas. In: Odzer R, Golblum JR, Crawford JM, editors. Surgical pathology of the GI track, liver, biliary tract and pancreas. Philadelphia: Saunders; 2004.

2. Jemal A, Siegel R, Ward E, Murray T, Xu J, Thun MJ. Cancer Statistics, 2007. CA Cancer J Clin 2007;57:43-66.

3. El-Rayes BF, Philip PA. A review of systemic therapy for advanced pancreatic cancer. Clin Adv Hematol Oncol 2003;1:430-4.

4. Jemal A, Siegel R, Xu J, Ward E. Cancer Statistics, 2010. CA Cancer J Clin 2010;60:277-300.

5. Bloomston M, Frankel WL, Petrocca F, Volinia S, Alder H, Hagan JP, et al. MicroRNA expression patterns to differentiate pancreatic adenocarcinoma from normal pancreas and chronic pancreatitis. JAMA 2007;297:1901-8.

6. Drakaki A, Iliopoulos D. MicroRNA Gene Networks in Oncogenesis. Curr Genomics 2009;10:35-41.

7. Hatziapostolou M, Iliopoulos D. Epigenetic aberrations during oncogenesis. Cell Mol Life Sci 2011;68:1681-702.

8. Stagakis E, Bertsias G, Verginis P, Nakou M, Hatziapostolou M, Kritikos H, et al. Identification of novel microRNA signatures linked 
to human lupus disease activity and pathogenesis: miR-21 regulates aberrant $\mathrm{T}$ cell responses through regulation of PDCD4 expression. Ann Rheum Dis 2011;70:1496-506.

9. Iliopoulos D, Hirsch HA, Struhl K. An epigenetic switch involving NF-kappaB, Lin28, Let-7 MicroRNA, and IL6 links inflammation to cell transformation. Cell 2009;139:693-706.

10. Iliopoulos D, Jaeger SA, Hirsch HA, Bulyk ML, Struhl K. STAT3 activation of miR-21 and miR-181b-1 via PTEN and CYLD are part of the epigenetic switch linking inflammation to cancer. Mol Cell 2010;39:493-506.

11. Hatziapostolou M, Polytarchou C, Aggelidou E, Drakaki A, Poultsides GA, Jaeger SA, et al. An HNF4 $\alpha$-miRNA inflammatory feedback circuit regulates hepatocellular oncogenesis. Cell 2011;147:1233-47.

12. Bakirtzi K, Hatziapostolou M, Karagiannides I, Polytarchou C, Jaeger S, Iliopoulos $\mathrm{D}$, et al. Neurotensin signaling activates microRNAs-21 and -155 and Akt, promotes tumor growth in mice, and is increased in human colon tumors. Gastroenterology 2011;141:1749-61.

13. Calin GA, Dumitru CD, Shimizu M, Bichi R, Zupo S, Noch E, et al. Frequent deletions and down-regulation of micro- RNA genes miR15 and miR16 at 13q14 in chronic lymphocytic leukemia. Proc Natl Acad Sci U S A 2002;99:15524-9.

14. Bhatti I, Lee A, Lund J, Larvin M. Small RNA: A large contributor to carcinogenesis? J Gastrointest Surg 2009;13:1379-88.

15. Chan JA, Krichevsky AM, Kosik KS. MicroRNA-21 is an antiapoptotic factor in human glioblastoma cells. Cancer Res 2005;65:6029-33.

16. Volinia S, Calin GA, Liu CG, Ambs S, Cimmino A, Petrocca F, et al. A microRNA expression signature of human solid tumors defines cancer gene targets. Proc Natl Acad Sci U S A 2006;103:2257-61.

17. Lu J, Getz G, Miska EA, Alvarez-Saavedra E, Lamb J, Peck D, et al. MicroRNA expression profiles classify human cancers. Nature 2005;435:834-8.

18. Szafranska AE, Davison TS, John J, Cannon T, Sipos B, Maghnouj A, et al. MicroRNA expression alterations are linked to tumorigenesis and non-neoplastic processes in pancreatic ductal adenocarcinoma. Oncogene 2007;26:4442-52.

19. Kranenburg O. The KRAS oncogene: Past, present, and future. Biochem Biophys Acta 2005;1756:81-2.

20. Kern S, Hruban R, Hollingsworth MA, Brand R, Adrian TE, Jaffee E, et al. A white paper: The product of a pancreas cancer think tank. Cancer Res 2001;61:4923-32.

21. Bos JL. ras oncogenes in human cancer: A review. Cancer Res 1989;49:4682-9.

22. Young A, Lyons J, Miller AL, Phan VT, Alarcón IR, McCormick F. Ras signaling and therapies. Adv Cancer Res 2009;102:1-17.

23. Porfiri E, Evans T, Chardin P, Hancock JF. Prenylation of Ras proteins is required for efficient hSOS1-promoted guanine nucleotide exchange. J Biol Chem 1994;269:22672-7.

24. Gonzalez-Cadavid NF, Zhou D, Battifora H, Bar-Eli M, Cline MJ. Direct sequencing analysis of exon 1 of the c-K-ras gene shows a low frequency of mutations in human pancreatic adenocarcinomas. Oncogene 1989;4:1137-40.

25. Zhao WG, Yu SN, Lu ZH, Ma YH, Gu YM, Chen J. The miR-217 microRNA functions as a potential tumor suppressor in pancreatic ductal adenocarcinoma by targeting KRAS. Carcinogenesis 2010;31:1726-33.

Biomed J Vol. 36 No. 5

September - October 2013
26. Yu S, Lu Z, Liu C, Meng Y, Ma Y, Zhao W, et al. miRNA-96 suppresses KRAS and functions as a tumor suppressor gene in pancreatic cancer. Cancer Res 2010;70:6015-25.

27. Jiao LR, Frampton AE, Jacob J, Pellegrino L, Krell J, Giamas G, et al. MicroRNAs targeting oncogenes are down-regulated in pancreatic malignant transformation from benign tumors. PLoS One 2012; 7:e32068.

28. Kent OA, Fox-Talbot K, Halushka MK. RREB1 repressed miR-143/145 modulates KRAS signaling through downregulation of multiple targets. Oncogene 2013;32:2576-85.

29. du Rieu MC, Torrisani J, Selves J, Al Saati T, Souque A, Dufresne M, et al. MicroRNA-21 is induced early in pancreatic ductal adenocarcinoma precursor lesions. Clin Chem 2010;56:603-12.

30. Dillon RL, White DE, Muller WJ. The phosphatidyl inositol 3-kinase signaling network: Implications for human breast cancer. Oncogene 2007;26:1338-45.

31. Song G, Ouyang G, Bao S. The activation of Akt/PKB signaling pathway and cell survival. J Cell Mol Med 2005;9:59-71.

32. Schönleben F, Qiu W, Ciau NT, Ho DJ, Li X, Allendorf JD, et al. PIK3CA mutations in intraductal papillary mucinous neoplasm/ carcinoma of the pancreas. Clin Cancer Res 2006;12:3851-5.

33. Crespo P, Schuebel KE, Ostrom AA, Gutkind JS, Bustelo XR. Phosphotyrosine-dependent activation of Rac-1 GDP/GTP exchange by the vav proto-oncogene product. Nature 1997;385:169-72.

34. Takai Y, Sasaki T, Matozaki T. Small GTP-binding proteins. Physio Rev 2001;81:153-208.

35. Iliopoulos D, Polytarchou C, Hatziapostolou M, Kottakis F, Maroulakou IG, Struhl K, et al. MicroRNAs differentially regulated by Akt isoforms control EMT and stem cell renewal in cancer cells. Sci Signal 2009;2:ra62.

36. Ali S, Ahmad A, Banerjee S, Padhye S, Dominiak K, Schaffert JM, et al. Gemcitabine sensitivity can be induced in pancreatic cancer cells through modulation of miR-200 and miR-21 expression by curcumin or its analogue CDF. Cancer Res 2010;70:3606-17.

37. Zhang S, Hao J, Xie F, Hu X, Liu C, Tong J, et al. Downregulation of miR-132 by promoter methylation contributes to pancreatic cancer development. Carcinogenesis 2011;32:1183-9.

38. Crosnier C, Stamataki D, Lewis J. Organizing cell renewal in the intestine: Stem cells, signals and combinatorial control. Nat Rev Genet 2006;7:349-59.

39. Hart A, Papadopoulou S, Edlund H. Fgf10 maintains notch activation, stimulates proliferation, and blocks differentiation of pancreatic epithelial cells. Dev Dyn 2003;228:185-93.

40. Brou C, Logeat F, Gupta N, Bessia C, LeBail O, Doedens JR, et al. A novel proteolytic cleavage involved in Notch signaling: The role of the disintegrin-metalloprotease TACE. Mol Cell 2000;5:207-16.

41. Lammert E, Brown J, Melton DA. Notch gene expression during pancreatic organogenesis. Mech Dev 2000;94:199-203.

42. Büchler P, Gazdhar A, Schubert M, Giese N, Reber HA, Hines OJ, et al. The Notch signaling pathway is related to neurovascular progression of pancreatic cancer. Ann Surg 2005;242:791-800.

43. Wang Z, Zhang Y, Li Y, Banerjee S, Liao J, Sarkar FH. Down-regulation of Notch-1 contributes to cell growth inhibition and apoptosis in pancreatic cancer cells. Mol Cancer Ther 2006;5:483-93.

44. Nalls D, Tang SN, Rodova M, Srivastava RK, Shankar S. Targeting 
epigenetic regulation of miR-34a for treatment of pancreatic cancer by inhibition of pancreatic cancer stem cells. PLoS One 2011;6:e24099.

45. Ji Q, Hao X, Zhang M, Tang W, Yang M, Li L, et al. MicroRNA miR-34 inhibits human pancreatic cancer tumor-initiating cells. PLoS One 2009;4:e6816.

46. Sureban SM, May R, Lightfoot SA, Hoskins AB, Lerner M, Brackett DJ, et al. DCAMKL-1 regulates epithelial-mesenchymal transition in human pancreatic cells through a miR-200a-dependent mechanism. Cancer Res 2011;71:2328-38.

47. Bao B, Wang Z, Ali S, Kong D, Li Y, Ahmad A, et al. Notch-1 induces epithelial-mesenchymal transition consistent with cancer stem cell phenotype in pancreatic cancer cells. Cancer Lett 2011;307:26-36.

48. Brabletz S, Bajdak K, Meidhof S, Burk U, Niedermann G, Firat E, et al. The ZEB1/miR-200 feedback loop controls Notch signalling in cancer cells. EMBO J 2011;30:770-82.

49. Ferrara N, Gerber HP, LeCouter J. The biology of VEGF and its receptors. Nat Med 2003;9:669-76.

50. Kulshreshtha R, Ferracin M, Wojcik SE, Garzon R, Alder H, Agosto-Perez FJ, et al. A microRNA signature of hypoxia. Mol Cell Biol 2007;27:1859-67.

51. Greither T, Grochola LF, Udelnow A, Lautenschläger C, Würl P, Taubert H. Elevated expression of microRNAs 155, 203, 210 and 222 in pancreatic tumors is associated with poorer survival. Int J Cancer 2010;126:73-80.

52. Poliseno L, Tuccoli A, Mariani L, Evangelista M, Citti L, Woods K, et al. MicroRNAs modulate the angiogenic properties of HUVECs. Blood 2006;108:3068-71.

53. Nishizawa H, Ota K, Dohi Y, Ikura T, Igarashi K. Bach1-mediated suppression of p53 is inhibited by p19(ARF) independently of MDM2. Cancer Sci 2012;103:897-903.

54. Okamoto A, Demetrick DJ, Spillare EA, Hagiwara K, Hussain SP, Bennett WP, et al. Mutations and altered expression of p16INK4 in human cancer. Proc Natl Acad Sci U S A 1994;91:11045-9.

55. Attri J, Srinivasan R, Majumdar S, Radotra BD, Wig J. Alterations of tumor suppressor gene $\mathrm{p} 16 \mathrm{INK} 4 \mathrm{a}$ in pancreatic ductal carcinoma. BMC Gastroenterol 2005;5:22.

56. Goldstein AM, Fraser MC, Struewing JP, Hussussian CJ, Ranade K, Zametkin DP, et al. Increased risk of pancreatic cancer in melanoma-prone kindreds with p16INK4 mutations. N Engl J Med 1995;333:970-4

57. Jeong J, Park YN, Park JS, Yoon DS, Chi HS, Kim BR. Clinical significance of $\mathrm{p} 16$ protein expression loss and aberrant $\mathrm{p} 53$ protein expression in pancreatic cancer. Yonsei Med J 2005;46:519-25.

58. Aguirre AJ, Bardeesy N, Sinha M, Lopez L, Tuveson DA, Horner J, et al. Activated Kras and Ink4a/Arf deficiency cooperate to produce metastatic pancreatic ductal adenocarcinoma. Genes Dev 2003;17:3112-26.

59. Hanoun N, Delpu Y, Suriawinata AA, Bournet B, Bureau C, Selves J, et al. The silencing of microRNA 148a production by DNA hypermethylation is an early event in pancreatic carcinogenesis. Clin Chem 2010;56:1107-18.

60. Zhao G, Zhang JG, Liu Y, Qin Q, Wang B, Tian K, et al. miR-148b Functions as a Tumor Suppressor in Pancreatic Cancer by Targeting AMPK $\alpha 1$. Mol Cancer Ther 2013;12:83-93.

61. Lodygin D, Tarasov V, Epanchintsev A, Berking C, Knyazeva T,
Körner $\mathrm{H}$, et al. Inactivation of miR-34a by aberrant $\mathrm{CpG}$ methylation in multiple types of cancer. Cell Cycle 2008;7:2591-600.

62. Park JK, Henry JC, Jiang J, Esau C, Gusev Y, Lerner MR, et al. miR-132 and miR-212 are increased in pancreatic cancer and target the retinoblastoma tumor suppressor. Biochem Biophys Res Commun 2011;406:518-23.

63. Kaur A, Dasanu CA. Targeting the HER2 pathway for the therapy of lower esophageal and gastric adenocarcinoma. Expert Opin Pharmacother 2011;12:2493-503.

64. Lei S, Appert HE, Nakata B, Domenico DR, Kim K, Howard JM. Overexpression of HER2/neu oncogene in pancreatic cancer correlates with shortened survival. Int J Pancreatol 1995;17:15-21.

65. Büchler P, Reber HA, Büchler MC, Roth MA, Büchler MW, Friess H, et al. Therapy for pancreatic cancer with a recombinant humanized anti-HER2 antibody (herceptin). J Gastrointest Surg 2001;5:139-46.

66. Talar-Wojnarowska R, Malecka-Panas E. Molecular pathogenesis of pancreatic adenocarcinoma: Potential clinical implications. Med Sci Monit 2006;12:RA186-93.

67. Huang TH, Wu F, Loeb GB, Hsu R, Heidersbach A, Brincat A, et al. Up-regulation of miR-21 by HER2/neu signaling promotes cell invasion. J Biol Chem 2009;284:18515-24

68. Polizio AH, Chinchilla P, Chen X, Manning DR, Riobo NA. Sonic Hedgehog activates the GTPases Rac1 and RhoA in a Gli-independent manner through coupling of smoothened to Gi proteins. Sci Signal 2011;4:pt7.

69. Ayers KL, Thérond PP. Evaluating Smoothened as a G-protein-coupled receptor for Hedgehog signaling. Trends Cell Biol 2010;20:287-98.

70. Kasper M, Regl G, Frischauf AM, Aberger F. GLI transcription factors: Mediators of oncogenic Hedgehog signaling. Eur J Cancer 2006;42:437-45

71. Dosch JS, Pasca di Magliano M, Simeone DM. Pancreatic cancer and hedgehog pathway signaling: New insights. Pancreatology 2010;10:151-7.

72. Luo G, Long J, Cui X, Xiao Z, Liu Z, Shi S, et al. Highly lymphatic metastatic pancreatic cancer cells possess stem cell-like properties. Int J Oncol 2013;42:979-84

73. Tsuda N, Ishiyama S, Li Y, Ioannides CG, Abbruzzese JL, Chang DZ Synthetic microRNA designed to target glioma-associated antigen 1 transcription factor inhibits division and induces late apoptosis in pancreatic tumor cells. Clin Cancer Res 2006;12:6557-64.

74. Zhang L, Jamaluddin MS, Weakley SM, Yao Q, Chen C. Roles and mechanisms of microRNAs in pancreatic cancer. World J Surg 2011;35:1725-31.

75. Mees ST, Mardin WA, Wendel C, Baeumer N, Willscher E, Senninger N, et al. EP300-a miRNA-regulated metastasis suppressor gene in ductal adenocarcinomas of the pancreas. Int J Cancer 2010;126:114-24.

76. Mees ST, Mardin WA, Sielker S, Willscher E, Senninger N, Schleicher C, et al. Involvement of CD40 targeting miR-224 and miR-486 on the progression of pancreatic ductal adenocarcinomas. Ann Surg Oncol 2009;16:2339-50.

77. Li Y, Vandenboom TG $2^{\text {nd }}$, Wang Z, Kong D, Ali S, Philip PA, et al. miR-146a suppresses invasion of pancreatic cancer cells. Cancer Res 2010;70:1486-95.

78. Wang F, Xue X, Wei J, An Y, Yao J, Cai H, et al. hsa-miR-520h downregulates $\mathrm{ABCG} 2$ in pancreatic cancer cells to inhibit migration, invasion, and side populations. Br J Cancer 2010;103:567-74. 
79. Yan H, Wu J, Liu W, Zuo Y, Chen S, Zhang S, et al. MicroRNA-20a overexpression inhibited proliferation and metastasis of pancreatic carcinoma cells. Hum Gene Ther 2010;21:1723-34.

80. Gregory PA, Bert AG, Paterson EL, Barry SC, Tsykin A, Farshid G, et al. The miR-200 family and miR-205 regulate epithelial to mesenchymal transition by targeting ZEB1 and SIP1. Nat Cell Biol 2008;10:593-601.

81. Burris HA $3^{\text {rd }}$, Moore MJ, Andersen J, Green MR, Rothenberg ML, Modiano MR, et al. Improvements in survival and clinical benefit with gemcitabine as first-line therapy for patients with advanced pancreas cancer: A randomized trial. J Clin Oncol 1997;15:2403-13.

82. Conroy T, Desseigne F, Ychou M, Bouché O, Guimbaud R, Bécouarn Y, et al. FOLFIRINOX versus gemcitabine for metastatic pancreatic cancer. N Engl J Med 2011;364:1817-25.

83. Dillhoff M, Liu J, Frankel W, Croce C, Bloomston M. MicroRNA-21 is overexpressed in pancreatic cancer and a potential predictor of survival. J Gastrointest Surg 2008;12:2171-6.
84. Moriyama T, Ohuchida K, Mizumoto K, Yu J, Sato N, Nabae T, et al. MicroRNA-21 modulates biological functions of pancreatic cancer cells including their proliferation, invasion, and chemoresistance. Mol Cancer Ther 2009;8:1067-74.

85. Hwang JH, Voortman J, Giovannetti E, Steinberg SM, Leon LG, Kim YT, et al. Identification of microRNA-2 1 as a biomarker for chemoresistance and clinical outcome following adjuvant therapy in resectable pancreatic cancer. PLoS One 2010;5:e10630.

86. Chang TC, Wentzel EA, Kent OA, Ramachandran K, Mullendore M, Lee KH, et al. Transactivation of miR-34a by p53 broadly influences gene expression and promotes apoptosis. Mol Cell 2007;26:745-52.

87. Gironella M, Seux M, Xie MJ, Cano C, Tomasini R, Gommeaux J, et al. Tumor protein 53-induced nuclear protein 1 expression is repressed by miR-155, and its restoration inhibits pancreatic tumor development. Proc Natl Acad Sci U S A 2007;104:16170-5. 